\title{
Correction of Poland Syndrome (Chest Hypoplasia) Using Polymethylmethacrylate Implant
}

\author{
Roberto Chacur*1, Honório Sampaio Menezes², Nívea Maria Bordin da Silva Chacur ${ }^{3}$, Danuza Dias \\ Alves $^{4}$, Rodrigo Cadore Mafaldo ${ }^{5}$, Leandro Dias Gomes ${ }^{6}$, Alexandre Peruzzo ${ }^{7}$ and Gisele Dos Santos \\ Barreto $^{8}$ \\ ${ }^{1}$ Surgeon, Leger Clinic, Rio de Janeiro, Brazil \\ ${ }^{2} \mathrm{PhD}$ in medicine, Leger Clinic, São Paulo, Brazil
}

${ }^{3} \mathrm{MD}$, Leger Clinic, Rio de Janeiro, Brazil

${ }^{4} \mathrm{MD}$, Leger Clinic, Porto Alegre, Brazil

${ }^{5}$ Surgeon, Leger Clinic, Brazil

${ }^{6}$ Surgeon, Leger Clinic, Porto Alegre, Brazil

${ }^{7}$ Plastic Surgeon, Porto Alegre, Brazil

${ }^{8}$ Biomedical Scientist, Leger Clinic, Porto Alegre, Brazil

*Corresponding author: Roberto Chacur, Surgeon, Leger Clinic, Brazil

\section{ARTICLE INFO}

Received: 豐 January 31, 2019

Published: 㓞 February 05, 2019

Citation: Roberto C, Honório Sampaio M, Nívea Maria Bordin da Silva C, Danuza Dias A, Rodrigo Cadore M et al. Correction of Poland Syndrome (Chest Hypoplasia) Using Polymethylmethacrylate Implant. Biomed J Sci \& Tech Res 14(1)-2019. BJSTR. MS.ID.002493.
ABSTRACT

Poland syndrome is a rare disease characterized by unilateral underdevelopment or absence of the chest muscle. Several techniques are used to correct the chest deformity.

Objective: To describe a minimally invasive treatment option, with the use of polymethylmethacrylate (PMMA), for difficult-to-treat deformities caused by Poland Syndrome.

Methods: PMMA was percutaneously implanted using a microcannula, after local anesthesia and with the patient awake. The volume of the implant was administered gradually, until the deformity was corrected. The patient returned to normal life immediately after the procedure, without the need for hospitalization.

Conclusion: In addition to being an effective option in aesthetic correction of the deformity, the use of PMMA reduced the risk of scarring and obtained satisfactory aesthetic result.

Keywords: Poland Syndrome; Breast Implantation; Polymethylmethacrylate; Abnormalities

\section{Introduction}

Poland anomaly (PA), also known as Poland syndrome, was first described by Alfred Poland as a unilateral underdevelopment or absence of the chest muscle, often associated with deformities such as syndactyly and chest wall deformity [1,2] Poland syndrome is characterized by a variable clinical presentation. The classical deformity consists of unilateral hypoplasia or aplasia of the sternocostal head of pectoralis major muscle and ipsilateral hand malformations. In addition, hypoplasia or aplasia of the breast is observed on the affected side in women. This condition is rare and present since birth $[3,4]$. The defect affects primarily the sternal portion of the pectoral muscles, and the clavicular portion of the muscle remains often unchanged [1,3] According to the National Human Genome Research Institute, the incidence is three times higher in males, and twice more frequent on the right side, and may even be associated with ipsilateral brachydactyly [3] Absence or decrease of hair, absence of the mammary gland, decreased nipple, more retractable or adherent skin and less subcutaneous tissue are characteristics that may also be associated with less muscle development [3].

The etiology is unknown, but the condition is most likely due to a decrease in blood flow in the region during embryonic development. Several studies suggest that a vascular change, caused by maternal 
smoking during pregnancy, occurs more precisely in the fourth month of pregnancy, when the vascular and lymphatic systems are formed. A decrease in subclavian artery blood flow can cause the anomalies that characterize the syndrome, such as atrophy of the affected region [1,3]. The aesthetic aspect is in general the most severe problem of the syndrome, but does not affect cognition, although there is relationship with other morphological changes $[1,3]$. Some associated systemic effects contribute with the correct diagnosis of the syndrome. Such changes can be observed and should be investigated during anamnesis, namely: gastrointestinal abnormalities, dextrocardia, diaphragmatic defect, change in the ipsilateral arm (size of the humerus, radius and ulna), biliary abnormality, oligodactyly (absence of fingers), syndactyly, costal arch abnormality, upper limb asymmetry, abnormal scapula, renal alteration or agenesis, encephalocele, microcefalia, vesicoureteral reflux and vertebral change $[1,3]$.

The deformities in the hands are more evident at birth than chest wall abnormalities [5]. It is important to stress that, although the changes described above must be investigated, Poland syndrome is generally characterized only by underdeveloped muscles [5]. The aesthetic problem is important and becomes more uncomfortable during adolescence. In female patients, chest deformity becomes more evident during adolescence as the absence or asymmetry of the developing breasts occurs. In male patients, although the chest does not develop in adolescence, the chest wall deformity causes great suffering, having a negative effect in social situations, including the use of swim and sports suits.

\section{Case Report}

The patient P.C.R., 37 years of age, was received at Clínica LEGER, in Porto Alegre, on February 012011 at 1:30 pm. The patient presented total agenesis of the right pectoral muscle, but other systemic changes or symptoms were not reported. After diagnosis of Poland syndrome, a treatment based on bioplasty combined with ipsilateral tissue detachment, permanent epilation on the left side was suggested. A plastic surgeon was indicated to perform mastopexy to correct the contralateral gynecomastia presented by the patient.

\section{Treatment}

The treatmentwasconducted bybioplasty ofthepectoralmuscles using a total volume of $420 \mathrm{ml}$ of $30 \%$ polymethylmethacrylate (PMMA). This volume of PMMA was implanted in five monthly sessions, combined with the detachment of the ipsilateral tissue and contralateral mastopexy. In each session, a total of $90 \mathrm{ml}$ of PMMA was administered, except for the fourth session in which the volume implanted was $60 \mathrm{ml}$. After the fourth session, the plastic surgeon performed the contralateral mastopexy. Complications such as hematoma formation and local infection were observed and properly treated. Ultrasound examination of the region showed the presence of small anechoid collections of around $1.2 / 0.7 \mathrm{~cm}$ on the $3 \mathrm{~h}$-axis, and 1.0/1.3 cm on the retroareolar region.
No other alterations were observed. The patient was followed up for seven months, with appropriate treatment until the complications described above were resolved. Currently, the patient is still under follow-up without any adverse symptom (Figure 1). The aesthetic result of the treatment of Poland syndrome with implantation of PMMA was successful, with virtually no scar formation (Figure 1). The procedure is minimally invasive and allows a fast recovery, without the need for hospitalization or limitation in daily life activities. Brazilian companies produce polymethylmethacrylate with quality and affordable price, making the procedure viable even with the need of a considerable volume to achieve satisfactory results. Problems with skin adhesion can be treated with gradual tissue detachment in multiple sessions, with 30-day intervals between sessions. Hematoma and seroma represent the major complications of this technique, since asymmetry of hair density can be compensated by use of laser for permanent hair removal.

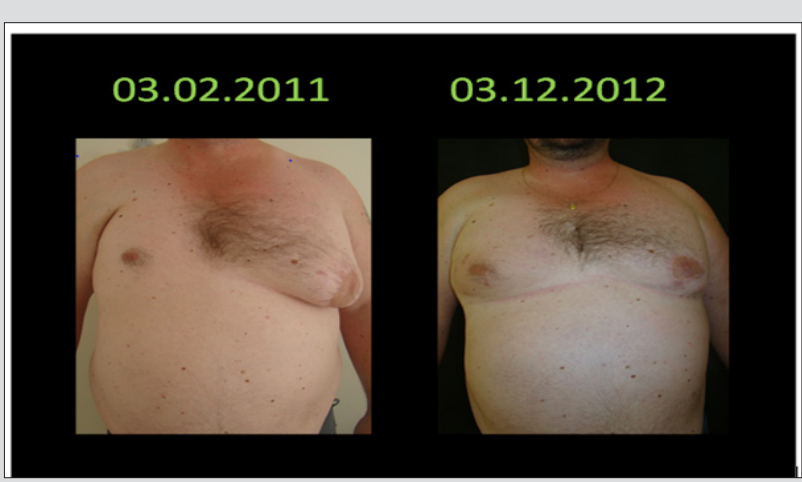

Figure 1: Before and after treatment.

\section{Discussion}

Although Poland syndrome is diagnosed mainly by clinical criteria, complementary analyses such as radiography, computed tomography and/or magnetic resonance imaging allow the investigation of the involvement of other organs and the mapping of the region before defining the treatment $[1,3]$. In the present case, no further tests were conducted and the patient did not present other complaints. The treatment can combine different methods, where appropriate, which are able to treat both the breasts and the chest wall (breast implants, muscle flaps). More recently, autologous fat cells have been implanted in these cases, according to the Coleman method [2]. In female patients, the treatment can be started only after mammary development has been completed, whereas in males it should be conducted as early as possible. The most common type of surgery used to treat female patients has been breast reconstruction with silicone implant $[1,3,6]$. In a study of the radiological appearance of normal and pathological results of mammary implantation of autologous fat, Constantini et al. [4] observed fatty cysts and fat necrosis, with and without calcification, related to the volume of injected fat. The product used in the present case can also, theoretically, generate granulomas and calcifications, similar to the effects of implanted fat. The option of autologous fat 
implant in a male patient, as in this case, it is not always feasible because of the difficulty of finding a donor site. Costa et al [5] observed that the deformity caused by the absence of sternocostal part of pectoralis major muscle can be corrected, with aesthetic purpose, by a latissimus dorsi pedicled flap or myocutaneous flap, in case of breast implant surgery $[1,3]$.

Expanders and implants, transposition of latissimus muscle flaps (when not affected by the syndrome), and rectus abdominis muscle flaps, in case of absence of the latissimus dorsi, are alternatives that have been proposed to restore the breast volume [7-9]. These techniques can achieve excellent results depending on the degree of deformation, but the aesthetic results of reconstruction of the anterior axillary pillar and the filling of the infraclavicular fossa have been disappointing [10]. Furthermore, an additional scar is left in the donor region of those muscular flaps. In addition to the scar, latissimus dorsi myocutaneous flap also results in an additional dorsal contour deformity due to the absence of muscle, which fills the posterior axillary pillar.

The effect of the absence of latissimus dorsi is subtle, but it can be very uncomfortable depending on the clothing worn by the patient. Such sequelae of treatment were among the reasons why a PMMA implant was used in the present case, despite an inevitable scar on the contralateral side due to mastopexy for correction of gynecomastia. Over a period of 12 years beginning in 1998, Costa et al. [5] followed up 15 Poland syndrome patients, who were treated for breast and chest wall deformities using the technique of transposition of omental flap harvested by videolaparoscopy. The resulting consistency is very similar to that of the contralateral breast, with better repair of the anterior axillary pillar than any other reconstructive technique. The difficulty of this technique is the inability to accurately determine the final volume available of omentum, at the time of planning the surgery. In the case reported here, there was no need of hospitalization or postprandial discomfort, and different from the study reported by Costa et al. [5] there was no difficulty in calculating the final volume.

Yang et al. [6] treated a Poland syndrome patient with several sequential injections of autologous fat tissue compressed by centrifugation, with better results in the maintenance of volume and reduction of complications, which in the case were only small cysts and calcifications. After four months follow-up, our patient has had no complaints. Fekih et al. [8] conducted a study in which eight patients with Poland syndrome (seven female) were operated between 1997 and 2008. The average age of patients was 22 years. According to the classification of Foucras et al. [9], four patients presented grade II Poland syndrome, three had grade I and two patients had grade III. Three of the patients (two with grade II and one with grade III Poland syndrome) received silicone implants. One teenage male patient, who was too embarrassed by his deformity, was treated with autologous fat injection. Three patients with moderate breast asymmetry were treated by contralateral liposuction, and the last patient, by resection of the contralateral breast. Intra- or postoperative complications were observed in eight patients. The aesthetic results were in general satisfactory.

PMMA filling in large volumes has been reported even for replacement of gluteal prosthesis without adverse effect observed after five years of follow-up [13] and also in other regions of the body such as arm, chest and back for both aesthetic and reconstructive purposes in patients traumatized and with sequelae [14]. The results include more attractive contours and volumetric repositioning compromised by the action of time.

\section{Conclusion}

In conclusion, our results show that the treatment of Poland syndrome using polymethylmethacrylate implant, in addition to being an effective alternative for aesthetic correction of the deformity, reduced the risk of scarring and had a satisfactory aesthetic result.

\section{References}

1. Martínez Frías ML, Czeizel AE, Rodríguez Pinilla E, Bermejo E (1999) Smoking during pregnancy and Poland sequence: results of a population-based registry and a case-control registry. Teratology 59(1): 35-38.

2. Pinsolle V, Chichery A, Grolleau JL, Chavoin JP(2008) Autologous fat injection in Poland ss syndrome. J Plast Reconstr Aesthet Surg 61(7): 784-791.

3. Karnak I, Tanyel FC, Tunçbilek E, Unsal M, Büyükpamukçu N (1998) Bilateral Poland anomaly. Am J Med Genet 75(5): 505-557.

4. Costantini M, Cipriani A, Belli P, Bufi E, Fubelli R, et al. (2013) Radiological findings in mammary autologous fat injections: a multitechnique evaluation. Clin Radiol 68(1): 27-33.

5. Yang H, Lee H (2011) Successful use of squeezed-fat grafts to correct a breast affected by Poland syndrome. Aesthetic Plast Surg 35(3): 418-25.

6. Fijałkowska M, Antoszewski B (2011) Surgical treatment of patients with Poland's syndrome--own experience. Pol Przegl Chir 83(12): 662627.

7. Seyfer AE, Icochea R, Graeber GM (1198) Poland's anomaly. Natural history and long-term results of chest wall reconstruction in 33 patients. Ann Surg 208(6): 776-782.

8. Gatti JE (1997) Poland's deformity reconstructions with a customized, extrasoft silicone prosthesis. Ann Plast Surg 39(2): 122-130.

9. Rintala AE, Nordstrom RE (1989) Treatment of severe developmental asymmetry of the female breast. Scand J Plast Reconstr Surg Hand Surg 23(3): 231-235.

10. Costa S, Blotta R, Mariano M, Meurer L, Edelweiss M (2010) Aesthetic Improvements in Poland's Syndrome Treatment with Omentum Flap. Aesth Plast Surg 34: 634-639.

11. Fekih M, Mansouri Hattab N, Bergaoui D, Chaieb A, Fikry T, et al. (2010) Correction of breast Poland's anomalies. About eight cases and literature review. Ann Chir Plast Esthet 55(3): 211-218.

12. Foucras L, Grolleau RaouxJL, Chavoin JP (2003) Poland's syndrome: clinic series and thoraco-mammary reconstruction. Report of 27 cases. Ann Chir Plast Esthet 48(2): 54-66.

13. Chacur R, Menezes HS, Chacur NN MSB, Alves DD, Mafaldo RC, et al. (2019) Replacement of gluteal implants by polymethyl methacrylate filler: case report. Case Reports in Plastic Surgery and Hand Surgery.

14. Chacur R (2018) Ciência e arte do preenchimento / Roberto Chacur-1 ed Porto Alegre. RS:AGE 


\section{ISSN: 2574-1241}

DOI: 10.26717.BJSTR.2019.14.002493

Roberto Chacur.Biomed J Sci \& Tech Res

(C) This work is licensed under Creative

Submission Link: https://biomedres.us/submit-manuscript.php

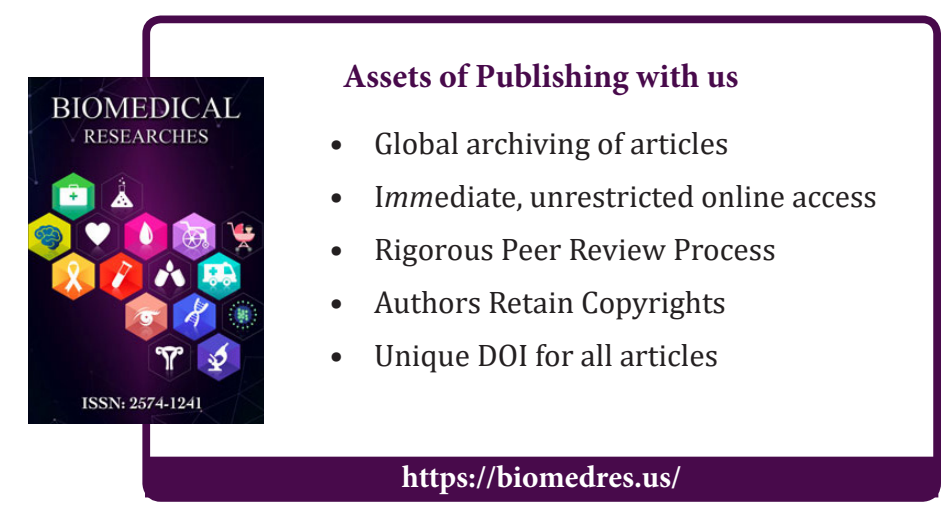

